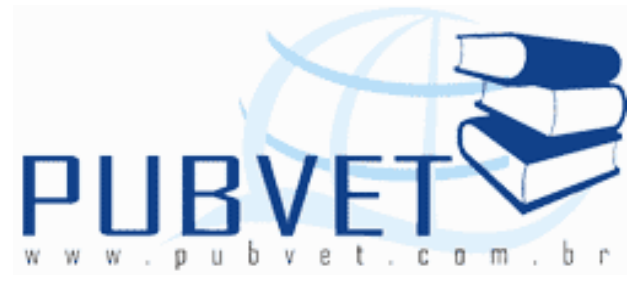

PUBVET, Publicações em Medicina Veterinária e Zootecnia.

\title{
Prevalência de lesões sugestivas de tuberculose em bubalinos abatidos no Amapá, Brasil
}

Luciana Barreto de Almeida Silva ${ }^{1}$, Claudiana Esteves ${ }^{2}$, Peter Bitencourt Faria ${ }^{3}$, Jacyara Thais Teixeira ${ }^{4}$, Thiago Santos Araújo ${ }^{5}$

${ }^{1}$ Médica Veterinária. Fiscal Agropecuária do Estado do Amapá. Agência de Defesa e Inspeção Agropecuária do Amapá - DIAGRO. .

${ }^{2}$ Médica Veterinária. Aluna de Mestrado em Ciências Veterinárias, Universidade Federal de Lavras/DMV, claudianaesteves@yahoo.com.br

${ }^{3}$ Médico Veterinário. Professor Adjunto da Universidade Federal de Lavras UFLA. Doutor em Ciências dos Alimentos. E-mail: peter@dmv.ufla.br

${ }^{4}$ Nutricionista. Aluna de Doutorado em Ciência dos Alimentos, Universidade Federal de Lavras/DCA. Doutor em Ciências dos Alimentos. E-mail: jacynutricao@yahoo.com.br

${ }^{5}$ Biólogo. Mestre em Ciências Veterinárias. E-mail: thiagobiocouto@gmail.com

\section{Resumo}

A tuberculose animal é de suma importância na saúde pública, uma vez que se trata de uma zoonose e o animal infectado pelo Mycobacterium sp é um transmissor da doença aos humanos através de seus produtos e subprodutos e que o consumo de carne bubalina é significativo na região amazônica, notadamente no Estado do Amapá, onde cerca de $65 \%$ da população bovídea é de bubalinos. Este trabalho teve como objetivo estudar a prevalência de 
condenações por lesões sugestivas de tuberculose em bubalinos abatidos no principal estabelecimento de abate de bovídeos que abastece a população amapaense. Consequentemente, alertar e sensibilizar a sociedade sobre a importância do controle da tuberculose animal e do consumo de produtos de origem animal inspecionados. Foram coletados dados de condenações por lesões sugestivas de tuberculose em carcaças e vísceras dos animais abatidos no Matadouro-frigorífico localizado no Município de Santana-AP, submetido ao controle SIE 0003, no período de setembro de 2010 a agosto de 2011. No período avaliado, observou-se uma prevalência de 2,95\%, pois de um total de 39.972 bubalinos abatidos, 1.179 apresentaram lesões compatíveis com tuberculose. Em 8,56\% dos casos as lesões se apresentaram de forma generalizada e $56,00 \%$ das carcaças condenadas procedem de animais da região de maior concentração de bubalinos do Estado do Amapá (municípios de Tartarugalzinho, Cutias do Araguari, Macapá e Amapá). Mediante os resultados obtidos torna-se imprescindível à implementação do Programa Nacional de Controle e Erradicação da Brucelose e Tuberculose Animal no Estado do Amapá para saneamento dos rebanhos.

Palavras-chave: Mycobacterium, bovídeos, inspeção.

\title{
Prevalence of tuberculosis in lesions suggestive of slaughtered in buffalo Amapa, Brazil
}

\begin{abstract}
The animal tuberculosis is of paramount importance for public health, since it is The animal tuberculosis is of paramount importance for public health, since it is a zoonosis and the animal infected by Mycobacterium sp is a transmitter of disease to humans through their products and by-products and the consumption of buffalo meat is significant in the region Amazon, especially in the State of Amapá, where about $65 \%$ of the population of buffaloes is bovídea, this work aimed to study the prevalence of convictions for lesions suggestive of tuberculosis in buffaloes slaughtered in the principal place of
\end{abstract}


slaughter of bovine fueling population Amapá. Consequently, to alert and sensitize society about the importance of the control of animal tuberculosis and consumption of animal products inspected. Data were collected from convictions for lesions suggestive of tuberculosis in carcasses and viscera of animals slaughtered in the slaughterhouse fridge located in the municipality of Santana - AP, subjected to the control SIE 0003, from September 2010 to August 2011. In the study period, there was a prevalence of $2.95 \%$, for a total of 39,972 buffaloes slaughtered, 1,179 showed lesions compatible with tuberculosis. In $8.56 \%$ of cases the lesions exhibited widely and $56.00 \%$ of carcasses condemned animals come from the region of higher concentration of buffaloes in the state of Amapá (municipalities Tartarugalzinho, Cutias of Araguari, Macapa and Amapá). From the results obtained it is essential to the implementation of the National Plan for Control and Eradication of Animal Brucellosis and Tuberculosis in the State of Amapá sanitation herds.

Keywords: Mycobacterium, bovine, inspection.

\section{INTRODUÇÃO}

A tuberculose causada pelo Mycobacterium bovis é uma doença infectocontagiosa de caráter zoonótico e evolução crônica que acomete principalmente bovinos e bubalinos. Caracteriza-se pelo desenvolvimento progressivo de lesões nodulares denominadas tubérculos, que podem localizarse em qualquer órgão ou tecido (BROLIO \& LIMA FILHO, 1976). Além dos bovideos, esse patógeno afeta outros hospedeiros, acometendo tanto os animais domésticos quanto silvestres e o homem.

Os Bubalinos têm temperamento dócil, o que facilita sua criação e manejo e se adaptam bem às condições ambientais úmidas. Como sua pele é preta com poucos pelos também pretos, sofrem muito quando estão sob a luz do sol, o que agrava ainda mais é a dificuldade que os bubalinos têm de dissipar o calor extracorpóreo em função do reduzido número de glândulas sudoríparas. Por esse motivo, em seu ambiente criatório, eles necessitam de 
açude ou lago para ficar mergulhado nas horas mais quentes do dia, tendo ainda como coadjuvante para a sua perfeita regulação térmica corpórea, áreas de sombra (ABCB, 2012).

Como segundo maior produtor de bubalinos do Brasil, atualmente o Amapá é o único estado brasileiro onde a exploração pecuária de bubalinos é predominante em relação à dos bovinos (MAPA, 2011), além do Brasil deter o maior rebanho da espécie do ocidente (VIEIRA, 2011).

A Tuberculose Bovina e a Bubalina são de notificação obrigatória, de acordo com art. 50, do Decreto 5.741/2006 que regulamenta o Programa Nacional de Controle e Erradicação da Brucelose e da Tuberculose Animal PNCEBT (BRASIL, 2006). No entanto, no Estado do Amapá ainda são escassos os rebanhos examinados e o Serviço de Inspeção de Produtos de Origem animal é a principal fonte de informação para se estimar a prevalência da doença em bovídeos.

A transmissão para os bovídeos ocorre principalmente pela via respiratória por meio da inalação de aerossóis contaminados com o microorganismo, água, pastagem e alimentos contaminados (ALMEIDA, 2010). A principal fonte de infecção para os rebanhos é o bovino ou o bubalino infectado, sendo a aquisição de animais infectados a via de introdução da Tuberculose em um rebanho.

A importância econômica atribuída à doença bovina está baseada nas perdas diretas e indiretas resultantes da morte de animais, queda no ganho de peso, diminuição da produção de leite, descarte precoce e eliminação de animais de alto valor zootécnico, além da condenação de carcaças no abate. Estima-se que os animais infectados com a tuberculose percam de $10 \%$ a $25 \%$ de sua eficiência produtiva. Existe ainda a perda de prestígio e credibilidade da unidade de criação onde a doença é constatada (COSTA, 2001; RIET-CORREA \& GARCIA, 2001; BRASIL, 2006).

De acordo com Moraes (1990), os prejuízos resultantes da tuberculose bubalina são enormes onde se desenvolve a bubalinocultura. A espécie 
bubalina é tão sensível à tuberculose quanto à espécie bovina (SIMOR, FREITAS e CAMPOS, 2006).

Em pesquisa realizada em búfalos abatidos em Belém-PA, o M. bovis foi a espécie predominante na identificação de cepas de Mycobacterium isoladas nas lesões e carcaças condenadas (FREITAS et al, 2001). No Estado do Pará é elevado o número de propriedades onde há animais infectados por M. bovis e a infeç̧ão por micobactérias de crescimento rápido é frequente em búfalos (RIBEIRO, 2003).

As manifestações clínicas da tuberculose são pouco específicas e geralmente mais tardias, o que restringe a possibilidade de utilização da semiologia para o diagnóstico individual, sendo a necropsia ou avaliação post mortem de carcaças, um recurso de grande importância no diagnóstico da tuberculose, para se confirmar a ocorrência da doença no rebanho, seja por meio das lesões granulomatosas características, seja por meio da coleta de material a ser utilizado para o isolamento (COSTA, 2008).

Dessa forma, o presente trabalho tem como objetivo estudar a prevalência de condenações por lesões sugestivas de tuberculose em bubalinos abatidos no principal estabelecimento de abate de bovídeos que abastece a população amapaense.

\section{MATERIAL E MÉTODOS}

A inspeção post mortem realizada pelo Serviço de Inspeção Estadual SIE do Amapá é feita em conformidade com Regulamento da Inspeção Industrial e Sanitária de Produtos de Origem Animal - RIISPOA (BRASIL, 2007). Os dados fornecidos foram registrados em planilhas de abate diários, transformados em relatórios mensais e anuais, todos preenchidos pelos médicos veterinários responsáveis e após impressos, enviados ao escritório central da Agência de Defesa e Inspeção Agropecuária do Estado do Amapá (DIAGRO). 
Para os estudos, foram utilizadas informações fornecidas pelos relatórios sobre o serviço de inspeção realizada no frigorífico submetido ao Serviço de Inspeção Estadual (SIE 0003), no período de setembro de 2010 a agosto de 2011. Estes dados geraram relatórios que possibilitaram a quantificação de animais que apresentam lesões sugestivas de tuberculose ao exame macroscópico. Pôde-se classificar o grau de extensão das lesões nas carcaças e nas vísceras dos animais desde lesões localizadas à generalizadas. Também foi observado o local (município) de procedência dos animais que tiveram suas carcaças condenadas por lesões de tuberculose.

Os dados dos relatórios de abate impressos foram tabulados e organizados em planilha de Excel $^{\circledR}$, sendo determinado o somatório e a porcentagem dos casos de condenação de carcaça e/ou vísceras que apresentavam lesões sugestivas de tuberculose, sendo utilizada análise descritiva para interpretação e discussão dos resultados.

\section{RESULTADOS E DISCUSSÃO}

No período avaliado, foram abatidos 49.871 bovídeos, dos quais 9.899 eram bovinos $(19,85 \%)$ e 39.972 bubalinos (80,15\%). A inspeção dos bubalinos revelou que deste total, 1.179 animais (2,95\%) apresentaram alterações sugestivas de tuberculose nas carcaças, cabeças ou em vísceras.

A taxa de prevalência geral encontrada no presente trabalho foi de 2,95\%. Em pesquisa realizada por Freitas, Guerra e Paneta (2001), foi encontrada à taxa de prevalência de $7,7 \%$ em búfalos abatidos para consumo em estabelecimento localizado na região metropolitana de Belém-PA. Contudo, é motivo de atenção do Serviço de Defesa Sanitária Animal e da Saúde Pública quando se observa o resultados de Moraes (1990), realizado no Município do Amapá-AP onde, dos 19 animais com reações positivas ao teste de tuberculina intradérmico caudal, 14 não apresentaram lesões visíveis ao abate, ou seja, foram reagentes sem lesão. Assim, de acordo com Baptista (2004) na rotina de inspeção, somente $47 \%$ das lesões tuberculosas macroscopicamente seriam 
detectáveis. Dessa forma, apesar deste índice de falha na detecção, quando não são utilizados métodos in vivo para deteç̧ão da doença no rebanho como ocorre nos estado, a inspeção de carcaças no abate se torna a principal de monitoramento.

$\mathrm{Na}$ Tabela 1 estão indicadas as localizações das lesões sugestivas de tuberculose encontradas nas carcaças e vísceras de bubalinos abatidos no Amapá.

Tabela 1 - Localização de lesões características de tuberculose nos animais abatidos no Matadouro-frigorífico com SIE 0003/AP no período de setembro de 2010 a agosto de 2011.

\section{Tipo de lesão/localização}

\section{$\mathrm{N}^{\circ} \mathrm{de}$}

casos

por área (\%)

\begin{tabular}{llcc}
\hline Generalizada & & 101 & 8,56 \\
\hline \multirow{2}{*}{ Localizada } & Carcaça & 59 & 5,00 \\
& $\begin{array}{l}\text { Cabeça } \\
\text { Vísceras vermelhas } \\
\text { (pulmões, coração, fígado) } \\
\text { Vísceras brancas (estômago, } \\
\text { intestinos) }\end{array}$ & 215 & 18,24 \\
& 35 & 65,22 \\
\hline
\end{tabular}

Fonte: DIAGRO (2011).

Os casos de generalização da tuberculose, ocorrem quando são encontradas lesões disseminadas em diversos órgãos e tecidos, o que é verificado também nos casos da tuberculose miliar, caracterizada por lesões granulomatosas dispersas por todo o peritônio e nas serosas dos órgãos viscerais. Esta forma da doença ocorre quando o tubérculo se abre para a luz 
SILVA, L.B.A. et al. Prevalência de lesões sugestivas de tuberculose em bubalinos abatidos no Amapá, Brasil. PUBVET, Londrina, V. 8, N. 12, Ed. 261, Art. 1732, Junho, 2014.

de um vaso sanguíneo e provoca um derrame muito grande de micobactérias na circulação que se alojam nos capilares de órgãos viscerais e dão origem a múltiplas lesões em praticamente todos os órgãos. Esta forma de tuberculose se caracteriza por granulomas pequenos de 2-3 mm de diâmetro dispersos nos órgãos viscerais e na superfície do peritônio e da pleura (COSTA, 2008).

Pode-se verificar que em $8,56 \%$ dos casos as lesões foram generalizadas nas carcaças. Freitas, Guerra e Paneta (2001), encontraram 27,9\% de lesões generalizadas em búfalos abatidos em Belém-PA. Provavelmente 0 alto percentual encontrado em 2001 deve-se ao PNCEBT (BRASIL, 2006) ainda não ter sido implementado no país e as medidas sanitárias para controle da tuberculose serem raras.

As lesões localizadas foram encontradas principalmente nas vísceras vermelhas $(65,22 \%)$, corroborando com os resultados encontrados por Freitas, Guerra e Paneta (2001) que relataram no aparelho respiratório um percentual de $60,3 \%$ dos casos; enquanto no conjunto cabeça-língua, foram 20,3\%; na carcaça, 9,6\%; na cavidade abdominal, 6,3\% e nas mamas, 3,8\%. A via respiratória é considerada como a principal porta de entrada da infecção em bovídeos (ALMEIDA, 2010).

De acordo com Costa (2008), as lesões tuberculosas no início da doença são encontradas geralmente nos pulmões e intestinos, os sítios primários de multiplicação que correspondem à porta de entrada do agente. A lesão inicial, denominada complexo primário que envolve o sítio de instalação do agente e o linfonodo local que drena a região é geralmente pequena e muitas vezes passa despercebida na necropsia dos animais. Contudo, a partir desta lesão inicial, o agente pode se disseminar para outros órgãos e tecidos, ocorrendo então a generalização da doença. Nesta fase, podem ser encontradas lesões granulomatosas (granulomas) nos pulmões, fígado, baço, rins, glândula mamária, linfonodos em geral, encéfalo e útero.

A Tabela 2 apresenta a distribuição dos casos de tuberculose de acordo com os municípios e estado de procedência dos animais abatidos no período em estudo. 
Tabela 2 - Número de carcaças condenadas por tuberculose em bubalinos abatidos no estabelecimento SIE 0003/AP no período de Setembro/2010 a Agosto/2011.

\begin{tabular}{lcc}
\hline \multicolumn{1}{c}{ Municípios } & Quantidade & $\mathbf{\%}$ \\
\hline Amapá- AP & 13 & 11 \\
$\begin{array}{l}\text { Calçoene-AP } \\
\text { Cutias }\end{array}$ & 01 & 1 \\
AraguariAP & 18 & 16 \\
Itaubal do Piririm & & \\
AP & 10 & 9 \\
Macapá - AP & 14 & \\
Pracuuba-AP & 02 & 12 \\
Tartarugalzinho-AP & 20 & 2 \\
Chaves-PA & 11 & 17 \\
Monte Alegre-PA & 01 & 10 \\
Prainha - PA & 10 & 1 \\
Almeirim-PA & 14 & 9 \\
\hline TOTAL & $\mathbf{1 3 4}$ & 12 \\
\hline
\end{tabular}

Fonte: DIAGRO (2011).

Os municípios do Estado do Amapá que apresentaram o maior número de carcaças com condenações como generalizadas para tuberculose foram Tartarugalzinho (17\%), Cutias de Araguari (16\%), Macapá (12\%) e Amapá $(11 \%)$. Todos são localizados na região de extensas áreas de várzea e juntos representam $70 \%$ da pecuária estadual.

De acordo com Figueiredo (2010), o tamanho do rebanho tem sido apontado como fator de risco para tuberculose bovina, de modo que a probabilidade de ocorrência da doença aumenta em função do tamanho dos rebanhos em decorrência de uma maior possibilidade de contato entre animais infectados e sadios. Segundo Abrahão (1999) os bovídeos eliminam o bacilo da 
SILVA, L.B.A. et al. Prevalência de lesões sugestivas de tuberculose em bubalinos abatidos no Amapá, Brasil. PUBVET, Londrina, V. 8, N. 12, Ed. 261, Art. 1732, Junho, 2014.

tuberculose no leite, expectoração, corrimento nasal, fezes, urina, secreções vaginais e uterinas e pelo sêmen. No Amapá esse contato se dá na época das chuvas, quando rebanhos de propriedades distintas se aglomeram nas áreas mais altas durante semanas até que as águas sequem, possibilitando o seu acesso à pastagem.

Dos animais provenientes do Estado do Pará, destacam-se os municípios de Almeirim (12\%), Chaves (10\%) e Prainha (9\%) com maior incidência de carcaças condenadas pela doença, sendo os dois últimos localizados no Arquipélago do Marajó. Corroborando com o trabalho realizado por Simor, Freitas e Campos (2006), realizado em matadouro localizado em Belém, onde foram estudadas as características da tuberculose em bovídeos procedentes de diversos criatórios regionais do Estado do Pará, estes autores observaram que os animais procedentes da Ilha do Marajó apresentaram números mais expressivos de lesões tuberculosas, principalmente os oriundos do município de Chaves-PA. No Estado do Amapá não existem matadouros com Serviço de Inspeção Federal - SIF ou com Serviço de Inspeção Municipal - SIM, havendo apenas dois matadouros com Serviço de Inspeção Estadual - SIE e para um estudo mais amplo, seria importante unir os dados de condenação de todos os animais abatidos no Estado e uma pesquisa de identificação do agente causador das lesões.

Torna-se necessário, portanto, fortalecer o Serviço de Defesa e Inspeção Sanitária Animal aumentando a quantidade de matadouros com serviço de inspeção, evitando que o produtor que tenha suas rezes diagnosticadas e condenadas passem a abater em estabelecimentos clandestinos, pondo em risco a saúde da população consumidora e principalmente dos trabalhadores desses estabelecimentos. Além disso, é imprescindível a criação de laticínios com exigência do exame negativo do rebanho para tuberculose animal para o recebimento do leite e o desenvolvimento de projetos de educação sanitária para conscientização do produtor rural sobre a importância do controle e erradicação dessa doença no estado. 
SILVA, L.B.A. et al. Prevalência de lesões sugestivas de tuberculose em bubalinos abatidos no Amapá, Brasil. PUBVET, Londrina, V. 8, N. 12, Ed. 261, Art. 1732, Junho, 2014.

\section{CONCLUSÕES}

O resultado obtido de $2,95 \%$ de prevalência de lesões sugestivas de tuberculose demonstra que a tuberculose é uma doença presente nos rebanhos amapaense e que é relevante à implantação do Programa Nacional de Controle e Erradicação da Brucelose e Tuberculose Animal no Estado para saneamento dos rebanhos.

O quadro nacional da bubalinocultura tende a mudar a médio e longo prazo tornando, assim, o búfalo um animal com tendência a crescimento da produção de carne, leite e derivados, com aumento da produtividade do rebanho nacional. Dessa forma, há a necessidade de maiores estudos nesta espécie, nas mais diversas áreas, como na biotecnologia da reprodução, doenças patológicas e hereditárias, identidade genética e controle qualidade de seus produtos.

\section{REFERÊNCIAS BIBLIOGRÁFICAS}

ABCB. ASSOCIAÇÃO BRASILEIRA DOS CRIADORES DE BÚFALOS. Disponível em: <http://www.bufalo.com.br/racas.html>. Acesso em: 28 out. 2013.

ABRAHÃO, R. M. C. Tuberculose humana causada pelo Mycobacterium bovis: considerações gerais e a importância dos reservatórios animais. São Paulo. Dissertação (Mestrado) - Faculdade de Saúde Pública, Universidade de São Paulo, 1999.

ALMEIDA, M. A. Z de. Tuberculose. In: Manual de zoonoses, 2 ed. v. 1. Porto Alegre: RS, 2010. p.142 a 162. Disponível em: < http://www.crmvrs.gov.br/Manual de Zoonoses I.pdf $>$. Acesso em: 28 out. 2013.

BAPTISTA, F. et al. Prevalência de tuberculose em bovinos abatidos em minas Gerais. Arq. Bras. Med. Vet. Zootec., v. 56, n. 5, p.577-580, 2004.

BRASIL. Ministério da Agricultura, Pecuária e Abastecimento. Manual Técnico do Programa Nacional de Controle e Erradicação da Brucelose e da Tuberculose - PNCEBT. Brasília/ SDA/DAS,2006. 184p.

BRASIL. Ministério da Agricultura, Pecuária e Abastecimento: Regulamento de Inspeção Industrial e Sanitária de Produtos de Origem Animal - RIISPOA e outras legislações de interesse do DIPOA. Brasília: SDA/DIPOA,2007. 252p.

BROLIO, R.; LIMA FILHO, M. T. Tuberculose pulmonar,. In: Veronesi R. (Ed), Doenças Infecciosas e Parasitárias. Guanabara Koogan, Rio de Janeiro. 1976. 317-361p. 
COSTA, G. M. Controle das Doenças de Bovinos: Brucelose e Tuberculose. Dissertação (pós-graduação) - Universidade Federal de Lavras -UFLA - Curso de Pós-graduação Lato Sensu Defesa Sanitária Animal, Lavras, 2008.

COSTA, M. Brucelose bovina e eqüina. In: RIET-CORREA F. et al. (Ed.). Doenças de ruminantes e eqüinos. 2.ed. São Paulo: Varela, 2001.

DIAGRO. Agência e Defesa e Inspeção Agropecuária do Amapá. Relatórios mensais do Estabelecimento de abate SIE 0003. Macapá: NIPOA, 2011.

FIGUEIREDO, S. M. et al. Tuberculose Bovina no Estado da Paraíba: estudo retrospectivo. Pesq. Vet. Bras. v. 30, n. 9, p. 712-716, Set., 2010.

FREITAS, J. A. GUERRA, J.L. PANETA, J.C. Características da tuberculose observada em búfalos abatidos para consumo: aspectos patológicos e identificação de micobactérias. Brazilian Journal Veterinary Research Animal Science. São Paulo, v.38, n.4, p.170-176, 2001.

MORAES, M.J. Rápidas observações sobre tuberculose em bubalinos. Associação de Assistência Técnica e Extensão Rural do Amapá, Macapá: AP, 1990,17 p.

RIBEIRO, A.C.C.L. Diagnóstico de tuberculose em búfalos (Bubalus bubalis). 2003. Dissertação (Doutorado em Ciência Natural). Escola Veterinária da Universidade Federal de Minas Gerais, Belo Horizonte, 2003.

RIET-CORREA, F.; GARCIA, M. Tuberculose. In: RIET-CORREA F. et al. (Ed.). Doenças de ruminantes e eqüinos. 2.ed. São Paulo: Varela, 2001.

SIMOR, E. D. L. C; FREITAS, J.A.; CAMPOS, E.D. Tuberculose em bovídeos abatidos para consumo. Rev. Ciênc. Agrár. Belém: PA, n. 45, p.267-281, jan. /jun. 2006.

VIEIRA, J.N., et al. Bubalinocultura no Brasil: Short communication. PUBVET, Londrina, v. 5, n. 2, ed. 149, art. 1003, 2011. 